\title{
Effect of Risperidone with Ondansetron to Control the Negative and Depressive Symptoms in Schizophrenia
}

Sara Mubeen ${ }^{1}$, Hafiz Muhammad Mudassar Aslam², Muhammad Tamour Danish ${ }^{3}$, Muhammad Imran ${ }^{*}, 4$ Aamira Hashmi ${ }^{5}$, Muhammad Hashim Raza ${ }^{4}$

${ }^{1}$ Manawan Hospital, Lahore, 54000, Pakistan

${ }^{2}$ General Hospital, Lahore, 54000, Pakistan

${ }^{3}$ Basic Health Unit, Awan Chak 39, District Kasur, 55050, Pakistan

${ }^{4}$ District Headquarter Hospital, Layyah, 31050, Pakistan

${ }^{5}$ District Headquarter Hospital, Muzaffargarh, 34200, Pakistan

\begin{tabular}{l} 
A R T I C L E I N F O \\
\hline Article history: \\
Received: 08 April, 2018 \\
Accepted: 24 May, 2018 \\
Online: 31 May, 2018 \\
\hline Keywords: \\
Schizophrenia \\
Risperidone \\
Depression \\
Negative symptoms \\
Ondansetron \\
\end{tabular}

A B S T R A C T
To evaluate the effects of Ondansetron on the negative and depressive symptoms of patients
with schizophrenia. A double-blind randomized control trial was conducted in 2016-17 in
Lahore. 30 participants were included both in placebo and medicine group. The patients
were assessed by using the Positive and Negative Syndrome Scale (PANSS) and Hamilton's
Rating Scale for Depression (HRSD) at baseline and at 12 weeks. The t-test and Chi square
test were used to evaluate the data by using SPSS (version 21). The statistical significance
was set at P $<0.05$. Ondansetron with risperidone has past impact on the negative symptoms
as compared to placebo with risperidone (P=0.002). There was a significant difference
between two groups after giving medicine and placebo as evaluated through WAIS-R scale.
Ondansetron had significantly improved the visual memory that was based upon subsets of
WAIS. Ondansetron has no role in the depressive symptoms (Effect size=0.15).
Ondansetron can be used for the treatment of negative symptoms that are suffering from
schizophrenia. It can be used as adjunctive therapy especially in cognitive impairment and
negative symptoms.

\section{Introduction}

Schizophrenia is a mental disorder characterized by the separation of thought processes and poor emotional awareness. Schizophrenia contains negative and positive symptoms. It is probably one of the enfeebling disorders [1]. Schizophrenia is different in its all aspects whether it is in clinical forms, prognosis, and response to treatment. There are hypotheses suggesting that dysfunction of the neurotransmitters plays a unique role in the onset and progress of the disease [2]. Although positive symptoms that are hallucinations, disorganized speech, delusions and thought are common, the negative symptoms of schizophrenia that are emotional withdrawal, bad rapport, blunted affect, lack of spontaneity, difficulties in abstract thinking and conversational flow are often more prominent [3].

*Corresponding Author: Muhammad Imran, District Headquarter Hospital Layyah, E-mail: imranmerani247@gmail.com
Cognitive impairment and negative symptoms are very important in impairment of occupation and social function [4]. Negative syndromes are diagnosed with interview-based measures, the Sans Assessment Scale (SANS) and Positive and Negative Syndrome Scale (PANSS). The negative symptoms are classified into 5 subscales: anhedonia, avolition, affective dullness, social isolation and alogia [5]. Main symptoms that are on negative side are often referred to as deficit disorder. Individuals with the deficit disorder have more cognitive deficits and poorer results than patients without it [6]. In spite of all the improvements in the treatment of schizophrenia, over the past decade, more researchers have been focusing on studying the negative symptoms of schizophrenia [7]. It is to be borne in mind that, apart from negative symptoms, depressive symptoms prevail in patients with schizophrenia [8].

The neurotransmitters involved in schizophrenia symptoms are dopamine, glutamate, gamma-aminobutyric acid, serotonin, 


\section{S. Mubeenlet al. / Advances in Science, Technology and Engineering Systems Journal Vol. 3, No. 3, 100-103 (2018)}

acetylcholine and histamine. 5 hydroxytryptamine or serotonin was the first neurotransmitter to be studied in schizophrenia. Antipsychotics act on serotonin usually by inhibiting their resumption. Ondansetron is used for the treatment of schizophrenia as it is an antagonist of the serotonin 5-HT3 receptor [9]. Ondansetron is often used in conjunction with other medicines to treat nausea and vomiting caused by cancer chemo-radiotherapy, anxiety, depression, surgery and migraine Headache [10]. Ondansetron may be an option for the treatment of negative symptoms, taking into account the etiological hypotheses associated with neurotransmitters [9-12]. Ondansetron affects the serotonergic system over the 5 HT3 receptors and in animal models and alcoholics, regardless of their type Effect on drinking behavior, has reduced depressive symptoms $[13,14]$, there may also be antidepressant activities in schizophrenic patients who have depressive symptoms, too. Results from experimental studies on the effects of Ondansetron on the negative symptoms of schizophrenia are scarce. We were unable to find studies investigating the antidepressant effects of Ondansetron in schizophrenia10. OCD and schizophrenia are somewhat clinically similar and are often comorbid $[15,16]$. On the other hand, there is some evidence on the Effect of Ondansetron on OCD [17]. There was found that Ondansetron plus risperidone is associated with a significantly larger improvement in the PANSS overall scale and subscales for negative symptoms and cognition than was risperidone plus placebo $(\mathrm{P}<0.001)$ [18]. The rationale of this study was to evaluate the effects of Ondansetron on the negative and depressive symptoms of patients with schizophrenia.

\section{Methodology}

A double-blind randomized controlled trial was conducted in one of the hospitals in Lahore. The study was approved by Ethical Committee of Services Hospital, Lahore. Duration of study was one year (2016-17). There were planned to enroll 30 patients were each group through purposive sampling [16]. Patients those are symptom-free from the psychotic episode since last two months were included in the study. Patients were included in the study after completion of DSM-IV-TR diagnosis, regardless of the type and stable phase of the schizophrenia. Schizophrenia was confirmed by three senior psychiatrists. Those patients who have cardiac and comorbid neurological disorder were excluded from the study. Patients having drug or alcohol dependency were also excluded from the study.

The first step of the study was to differentiate secondary symptoms from primary symptoms of the schizophrenia. Patients were evaluated through PANSS score before starting the treatment. Patients were evaluated through PANSS test after four weeks, those having no change $>20 \%$ were selected for the study. To exclude the patients from major depression and to evaluate the effect of Ondansetron on the depressive syndrome, Hamilton's Rating Scale for Depression (HRSD) was used.

Subjects were randomly selected through a simple random table after initial assessment and then divided into placebo and intervention group. All the patients were given risperidone with Ondansetron. Risperidone and Ondansetron were given to the patients for twelve weeks. Study population and staff were not aware of the placebo and intervention group. HRSD score, cognitive performance, and PANSS score were the outcome variables. SPSS version 21 was used to analyze the data. The parametric and non-parametric test was used to evaluate the results of the study. T-test and chi-square test were used for the analysis of data while the effect of variables was assessed through repeated measure design.

\section{Results}

There were total 60 study participants $(\mathrm{n}=30$ placebo group, $\mathrm{n}=30$ in the intervention group). Almost $80 \%(48 / 60)$ completed the treatment course of 12 weeks. Among the control nd experimental group, the mean age of participants was 41.21 (CI: 37.43 to 43.26 ) and 36.61 years (CI: 34.02 to 39.20 ), respectively. Age and sex of the study participants described in table 1.

Table 1: Demographic variables in the experimental and placebo groups

\begin{tabular}{|l|l|l|l|}
\hline Variables & $\begin{array}{l}\text { Experimental } \\
\text { group }\end{array}$ & Placebo group & P value \\
\hline $\begin{array}{l}\text { Frequency } \\
\text { (Percentage) }\end{array}$ & $\begin{array}{l}\text { Frequency } \\
\text { (Percentage) }\end{array}$ & \\
\hline Age & & & \\
\hline $\mathbf{2 0 - 4 0}$ & $17(57 \%)$ & $15(50)$ & 0.043 \\
\hline $\mathbf{4 0 - 6 0}$ & $13(43 \%)$ & $15(50)$ & \\
\hline Sex & & $20(66.7 \%)$ & 0.02 \\
\hline Male & $18(60 \%)$ & $10(33.3 \%)$ & \\
\hline Female & $12(40 \%)$ &
\end{tabular}

To compare whether Ondansetron has a significant effect on the negative symptoms, both groups were compared at two different intervals and there was the difference between two groups. The t-test results showed that there was a significant difference between two groups. There was also examined the negative symptoms before and after treatment given. Spontaneity and flow of conversation was the only negative symptom was there was no significant difference as results revealed in the Wilcoxon test. Negative symptoms and improvement in them are shown in table 2.

Table 2: Comparison of the effects of Ondansetron on different kinds of negative syndromes before and after the treatment in the experimental group by the Wilcoxon test

\begin{tabular}{|l|l|l|l|l|}
\hline Negative syndromes & \multicolumn{2}{|l|}{ Mean \pm SD } & $\begin{array}{l}\text { Mean and } \\
\text { difference }\end{array}$ & P value \\
\cline { 2 - 5 } & Before & After & 1.1 & $<0.002$ \\
\hline Blunted affect & $4.21 \pm 0.85$ & $3.11 \pm 6.22$ & 1.68 & $<0.003$ \\
\hline $\begin{array}{l}\text { Emotional } \\
\text { withdrawal }\end{array}$ & $4.11 \pm 0.44$ & $2.43 \pm 0.21$ & 1.38 & $<0.001$ \\
\hline Poor rapport & $4.31 \pm 0.52$ & $2.93 \pm 0.91$ & 0.64 & $<0.005$ \\
\hline $\begin{array}{l}\text { Passive/apathetic } \\
\text { social withdrawal }\end{array}$ & $3.14 \pm 0.52$ & $2.5 \pm 0.31$ & 0.001 \\
\hline $\begin{array}{l}\text { Difficulty in } \\
\text { abstract thinking }\end{array}$ & $4.41 \pm 0.7$ & $2.61 \pm 0.64$ & 1.8 & 0.31 \\
\hline $\begin{array}{l}\text { Lack of spontaneity } \\
\text { and flow of } \\
\text { conversation }\end{array}$ & $3.71 \pm 0.72$ & $3.43 \pm 0.47$ & 0.28 & $<0.001$ \\
\hline $\begin{array}{l}\text { Stereotyped } \\
\text { thinking }\end{array}$ & $3.93 \pm 0.55$ & $3.44 \pm 0.78$ & 0.49 & \\
\hline
\end{tabular}

To assess the placebo and medicine group, the HRSD results were assessed and resulted showed that there were no positive effects on the depression syndromes. When HRSD scores were compared for two groups apropos through repeated measures analysis, results showed no significant difference. Before and after 


\section{S. Mubeenlet al. / Advances in Science, Technology and Engineering Systems Journal Vol. 3, No. 3, 100-103 (2018)}

treatment, there was a significant difference in comprehension and object assembly.

Ondansetron was given to thirty patients, 19 (63\%) patients suffered from complications. Among 19 patients who suffered from complications, 7 suffered from constipation, 5 suffered from restlessness and insomnia and 7 others suffered from exhaustion confusion and nausea.

Table.3 Comparison of the effects of Placebo and Ondansetron on HRSD before and after treatment

\begin{tabular}{|l|l|l|l|}
\hline $\begin{array}{l}\text { Groups } \\
\text { Mean } \pm \text { SD } \\
\text { Confidence Interval }\end{array}$ & P value & $\begin{array}{l}\text { Effect } \\
\text { Size }\end{array}$ \\
\hline $\begin{array}{l}\text { Experimental Group } \\
\mathbf{1 5 . 2 1} \pm \text { 4.85 (10.36- } \\
\mathbf{2 0 . 0 6})\end{array}$ & $\begin{array}{l}\text { Placebo Group } \\
17.11 \pm 3.22(13.89-\end{array}$ & 0.62 & 0.15 \\
\hline $\begin{array}{l}\mathbf{1 4 . 1 1} \pm \mathbf{3 . 2 4}(\mathbf{1 0 . 8 7}- \\
\mathbf{1 7 . 3 5})\end{array}$ & $\begin{array}{l}16.33) \\
16.64)\end{array}$ & & \\
\hline $\mathbf{1 . 3 1} \pm \mathbf{0 . 0 2}(\mathbf{1 . 2 9 - 1 . 3 3 )}$ & $2.93 \pm 0.91(2.02-3.83)$ & 0.78 & \\
\hline
\end{tabular}

\section{Discussion}

In our study, ondansetron (4-8 $\mathrm{mg} /$ day) was supplemented with risperidone (4-6 mg/day) placebo plus risperidone after 12 weeks of treatment. Therefore, it is investigated the effects of ondansetron on verbal and performance intelligence using the WAIS-R test. In the subscales traceability and object assembly, many significant differences between the two groups has been found. In this study, ondansetron had no positive effect on depression symptoms (effect size $=0.15$ ).

Previous studies have shown that serotonin (5 HT) receptor antagonists have a therapeutic potential for schizophrenia [12, 19]. An article review of the effect of ondansetron on the treatment of schizophrenia in 2010 suggests that ondansetron is used in the treatment of schizophrenia. Treatment of schizophrenia might be effective, particularly negative symptoms. This rating is based on the assumption that risperidone is an active component of risperidone, which is the most common cause of rheumatoid arthritis-positive effects of ondansetron on the negative symptoms assessed with the PANSS [12].

In [20], authors used ondansetron to enhance the effects of clozapine in the treatment of schizophrenia, and their results indicated a significant difference between the two study groups. In [21], authors investigated the effects of the augmenting of haloperidol with ondansetron in patients with treatment-resistant schizophrenia, and reported that the group treated with ondansetron had a significantly higher proportion of subjects with a $30 \%$ improvement rate versus the initial value in the PANSS sum and dose negative scores, The results of the authors, thus also positive effects on the cognition, which coincide with our results. A meta-analysis based on limited data included ondansetron. However, in this review, ondansetron was not superior to the placebo in the PANSS-positive values, as it is found in the study [22]. In another study from 2014, the enhancement of the usual treatment of schizophrenia with ondansetron had positive but not significant Impact on the overall PANSS score [23].

In [24], authors showed that a short treatment period with ondansetron resulted in an improvement in visual memory in schizophrenia. In their crossover study, the authors aimed to study the effects of ondansetron on various memory tasks in patients with schizophrenia. The beneficial effects of ondansetron on memory and intelligence could be due to the exclusion of serotonin from presynaptic areas.

In [12], authors found that the combination of ondansetron with antipsychotic (risperidone) significantly improved visual memory, negative symptoms, and cognitive disorders in chronic schizophrenia. In [25], authors demonstrated the improvement of the effect of ondansetron alone or in combination with simvastatin on verbal and visual learning in the context of new learning. In [26], authors showed positive significant effects of ondansetron on visual memory regarding WAIS R data analysis. In another study, 5-HT3 receptor regulation has been shown to improve cognitive deficits and extrapyramidal side effects [27]. Similarly, in [28], authors investigated the efficacy of ondansetron in improving p50 auditory control in patients with schizophrenia.

Ondansetron did not have a positive effect on depression symptoms in our study. In contrast, a study in 2014 showed the therapeutic effect of ondansetron on depression in mice [14]. Another study argued that ondansetron might probably improve depression in alcoholics, probably due to its serotonergic effects [15]. In [29], authors reported on significant therapeutic effects of ondansetron on depression. Another study also highlighted the antidepressant effect of ondansetron on schizophrenia and other psychiatric disorders [30]. The different methods for evaluating depression can be the reason for the inconsistency of the results. Most studies have shown that ondansetron is well-tolerated without acute complications [11,32]. In [10], only 2 patients discontinued treatment due to aggression and insomnia. Some patients had minor complications such as insomnia, constipation, confusion, nausea, and fatigue. In our study, 2 subjects left the study due to ondansetron complications (insomnia and restlessness).

In schizophrenia, some factors can be correlated with a poorer prognosis. Empirical findings have confirmed that negative symptoms are related to the treatment prognosis [7]. Nevertheless, findings from experimental studies on the effects of ondansetron on the negative symptoms in schizophrenia are not clear. In addition, the degree of influence of negative symptoms on the treatment prognosis need not yet be fully clarified. It is also likely that factors that have an impact on negative symptoms will not be well understood. The serotonergic system is involved in schizophrenia and OCD. A review of the literature showed some therapeutic effects of ondansetron augmentation on the usual drug system of the treatment-resistant OCD [18], as is the case with the treatment of resistant schizophrenia [10]. Future studies could have a common pathway in the pathogenesis and treatment of schizophrenia and OCD in that sometimes schizophrenia prodrome is similar to OCD-like symptoms and there are similarities between the clinical manifestations of OCD and schizophrenia $[16,17]$. Some cognitive and negative components in schizophrenia can be the result of a comorbid OCD [17]. In fact, OCD can cause or stereotypical thinking and the social and emotional retreat in the final stages. Understanding and object composition and other neurocognitive tasks may be impaired by OCD $[16,17]$. 
Although a standard treatment for schizophrenia has emerged, many unanswered questions remain. An important question is whether ondansetron is sufficient to reduce negative symptoms in schizophrenia.

The present study also underlines the importance of experimental studies to identify brain mechanisms involved in cognition and neuropathology of schizophrenia. The knowledge of negative symptoms in schizophrenia is increasing and the number of studies in this area has increased to understand the nature of schizophrenia as well as the possibilities of their treatment.

In the current study, there are a number of limitations, including the relatively small sample size, which excludes a generalizability of the results to other populations without further studies. A further limitation was the incomplete compliance with the CONSORT standard for reporting clinical trials [30].

\section{Conclusion}

The results of the current study showed that the administration of ondansetron significantly improved negative symptoms and cognitive disorders. These preliminary results suggest that ondansetron may play a role to improve the symptoms of people with Schizophrenia. The study results confirmed that ondansetron, as an additional treatment conventional therapy, is particularly in negative symptoms. There are limitations of the study as it has a small sample size. There is need of more studies should be conducted to support this study and there will be a good addition in the literature to give more confidence to the scientist to use this combination of medicines.

\section{Conflict of Interest}

The authors declare no conflict of interest.

\section{References}

[1] Martin, E. Concise Medical Dictionary. 8th ed. New York: Oxford University Press; 2010.

[2] Wong DF. Molecular Brain Imaging in Schizophrenia. In: Sadock BJ, Sadock VA, Ruiz P, Kaplan HI, editors. Kaplan \& Sadock's comprehensive textbook of psychiatry. 9th ed. Phiadilphia: Lippocott Williams and willkins; 2009. p. 1527.

[3] van Os J, Kapur S. Schizophrenia. Lancet. 2009;374:635 45. doi: 10.1016/ S0140 6736(09)60995 8. PubMed PMID: 19700006.

[4] Bowie CR, Harvey PD. Cognition in schizophrenia: impairments, determinants, and functional importance. Psychiatr Clin North Am. 2005;28:613 33, 26. doi: 10.1016/j.psc.2005.05.004. PubMed PMID: 16122570 .

[5] Kirkpatrick B, Fischer B. Subdomains within the negative symptoms of schizophrenia: commentary. Schizophr Bull. 2006;32:246 9. doi: 10.1093/schbul/sbj054. PubMed PMID: 16492798; PubMed Central PMCID: PMC2632226.

[6] Stephen NL. Phenomenology of schizophrenia. In: In: Sadock BJ, Sadock VA, Ruiz P, Kaplan HI, editors. Kaplan \& Sadock's comprehensive textbook of psychiatry. Vol 2. Phiadilphia: Lippocott Williams and willkins; 2009. p. 143346.

[7] Makinen J, Miettunen J, Isohanni M, Koponen H. Negative symptoms in schizophrenia: a review. Nord J Psychiatry. 2008;62:334 41. doi: 10.1080/08039480801959307. PubMed PMID: 18752104.

[8] Castle DJ, Slott Jensen JK. Management of depressive symptoms in schizophrenia. Clin Schizophr Relat Psychoses. 2015;9:13 20. doi: 10.3371/CSRP.CAJE.103114. PubMed PMID: 25367164.

[9] Bennett AC, Vila TM. The role of ondansetron in the treatment of schizophrenia. Ann Pharmacother. 2010;44:1301 6. doi: 10.1345/aph.1P008. PubMed PMID: 20516364.

[10] Miyata K, Honda K. [Serotonin (5 HT) 3 receptors: antagonists and their pharmacological profiles]. Nihon Yakurigaku Zasshi. 1994;104:143 52. PubMed PMID: 7959407.
[11] Akhondzadeh S, Mohammadi N, Noroozian M, Karamghadiri N, Ghoreishi A, Jamshidi AH, et al. Added ondansetron for stable schizophrenia: a double blind, placebo controlled trial. Schizophr Res. 2009;107:206 12. doi: 10.1016/j.schres. 2008.08.004. PubMed PMID: 18789844.

[12] Lindenmayer JP, Bossie CA, Kujawa M, Zhu Y, Canuso CM. Dimensions of psychosis in patients with bipolar mania as measured by the positive and negative syndrome scale. Psychopathology. 2008;41:264 70. doi: 10.1159/000128325. PubMed PMID: 18441528.

[13] Gupta D, Radhakrishnan M, Kurhe Y. Ondansetron, a 5HT3 receptor antagonist reverses depression and anxiety like behavior in streptozotocin induced diabetic mice: possible implication of serotonergic system. Eur J Pharmacol. 2014;744:59 66. doi: 10.1016/j.ejphar.2014.09.041. PubMed PMID: 25284215.

[14] Johnson BA, Ait Daoud N, Ma JZ, Wang Y. Ondansetron reduces mood disturbance among biologically predisposed, alcohol dependent individuals. Alcohol Clin Exp Res. 2003;27:1773 9. doi: 10.1097/01. ALC.0000095635.46911.5D. PubMed PMID: 14634493.

[15] Bottas A, Cooke RG, Richter MA. Comorbidity and pathophysiology of obsessive compulsive disorder in schizophrenia: is there evidence for a schizo obsessive subtype of schizophrenia? J Psychiatry Neurosci. 2005;30:187 93. PubMed PMID: 15944743; PubMed Central PMCID: PMC1089779.

[16] Zink M. Comorbid Obsessive Compulsive Symptoms in Schizophrenia: Insight into Pathomechanisms Facilitates Treatment. Adv Med. 2014;2014:317980. doi: 10.1155/2014/317980. PubMed PMID: 26556409; PubMed Central PMCID: PMC4590963.

[17] Pittenger C, Bloch MH. Pharmacological treatment of obsessive compulsive disorder. Psychiatr Clin North Am. 2014;37:375 91. doi: 10.1016/j.psc.2014.05.006. PubMed PMID: 25150568; PubMed Central PMCID: PMC4143776.

[18] Samadi R, Soluti S, Daneshmand R, Assari S, Manteghi AA. Efficacy of Risperidone Augmentation with Ondansetron in the Treatment of Negative and Depressive Symptoms in Schizophrenia: A Randomized Clinical Trial. Iranian Journal of Medical Sciences. 2017;42(1):14-23.

[19] Briskin JK, Curtis JL. Augmentation of clozapine therapy with ondansetron. Am J Psychiatry. 1997;154:1171. PubMed PMID: 9247415.

[20] Zhang ZJ, Kang WH, Li Q, Wang XY, Yao SM, Ma AQ. Beneficial effects of ondansetron as an adjunct to haloperidol for chronic, treatment resistant schizophrenia: a double blind, randomized, placebo controlled study. Schizophr Res. 2006;88:102 10. doi: 10.1016/j.schres. 2006.07.010. PubMed PMID: 16959472.

[21] Kishi T, Mukai T, Matsuda Y, Iwata N. Selective serotonin 3 receptor antagonist treatment for schizophrenia: meta analysis and systematic review. Neuromolecular Med. 2014;16:61 9. doi: 10.1007/ s12017 01382510 . PubMed PMID: 23896722

[22] Chaudhry IB, Husain N, Drake R, Dunn G, Husain MO, Kazmi A, et al. Add on clinical effects of simvastatin and ondansetron in patients with schizophrenia stabilized on antipsychotic treatment: pilot study. Ther Adv Psychopharmacol. 2014;4:110 6. doi: 10.1177/2045125313511487. PubMed PMID: 25057343; PubMed Central PMCID: PMC4107703.

[23] Levkovitz Y, Arnest G, Mendlovic S, Treves I, Fennig S. The effect of Ondansetron on memory in schizophrenic patients. Brain Res Bull. 2005;65:291 5. doi: 10.1016/j. brainresbull. 2003.09.022. PubMed PMID: 15811593.

[24] Deakin J, Chaudhry I, Parker A, Dunn G, Kazmi A, Drake R, et al. Therapeutic Trials of Minocycline, Ondansetron and Simvastatin in Schizophrenia. European Psychiatry. 2015;30:71

[25] Mohammadi N, Noroozian M, Karamghadiri N, Akhondzadeh S. 5 HT3 antagonist for cognition improvement in schizophrenia: a double blind, placebo controlled trial. Basic Clin Neurosci. 2010;1:10 4

[26] Shimizu S, Mizuguchi Y, Ohno Y. Improving the treatment of schizophrenia: role of 5 HT receptors in modulating cognitive and extrapyramidal motor functions. CNS Neurol Disord Drug Targets. 2013;12:861 9. PubMed PMID: 23844689.

[27] Adler LE, Cawthra EM, Donovan KA, Harris JG, Nagamoto HT, Olincy A, et al. Improved p50 auditory gating with ondansetron in medicated schizophrenia patients. Am J Psychiatry. 2005;162:386 8. doi: 10.1176/appi.ajp.162.2.386. PubMed PMID: 15677607.

[28] Piche T, Vanbiervliet G, Cherikh F, Antoun Z, Huet PM, Gelsi E, et al. Effect of ondansetron, a 5 HT3 receptor antagonist, on fatigue in chronic hepatitis $\mathrm{C}$ : a randomised, double blind, placebo controlled study. Gut. 2005;54:1169 73 . doi: 10.1136/gut.2004.055251. PubMed PMID: 16009690; PubMed Central PMCID: PMC1774898.

[29] Bétry C, Etiévant A, Oosterhof C, Ebert B, Sanchez C, Haddjeri N. Role of 5 HT (3) Receptors in the Antidepressant Response. Pharmaceuticals. 2011;4:603 29. doi: 10.3390/ph 4040603. PubMed PMID: PMC4055881.

[30] Suvarna V. 'Consort 2010: a standard for reporting clinical trials revised anew? Perspect Clin Res. 2010;1:87 9. PubMed PMID: 21814625; PubMed Central PMCID: PMC3146077. 